Correction

\title{
Correction: Fu et al. Long-Term Atmospheric Visibility Trends and Characteristics of 31 Provincial Capital Cities in China during 1957-2016. Atmosphere, 2018, 9, 318
}

\author{
Weicong Fu 1,2,3,4 , Ziru Chen ${ }^{1}$, Zhipeng Zhu ${ }^{1}$, Qunyue Liu ${ }^{1,2}$, Jinda Qi ${ }^{5}$, Emily Dang ${ }^{4}$, \\ Minhua Wang ${ }^{1}$ and Jianwen Dong ${ }^{1, *}$ \\ 1 College of Landscape Architecture, Fujian Agriculture and Forestry University, Fuzhou 350002, China; \\ weicongfufj@163.com (W.F.); fjchenziru@126.com (Z.C.); zhuzhipeng512@126.com (Z.Z.); \\ fafulqy@gmail.com (Q.L.); wmh699@163.com (M.W.) \\ 2 Urban Forestry Research in Action, Department of Forest Resources Management, \\ The University of British Columbia, Vancouver V6T 1Z4, BC Canada \\ 3 Collaborative for Advanced Landscape Planning, Faculty of Forestry, The University of British Columbia, \\ Vancouver V6T 1Z4, BC Canada \\ 4 Faculty of Forestry, The University of British Columbia, Vancouver V6T 1Z4, BC Canada; \\ emily.dang@hotmail.com \\ 5 Faculty of built environment, University of New South Wales, Sydney 2052, Australia; \\ jinda.qi@student.unsw.edu.au \\ * Correspondence: fjdjw@fafu.edu.cn; Tel.: +86-0591-8378-9179
}

The authors would like to correct the published article [1]:

On page 3, Figure 1 should be changed from:

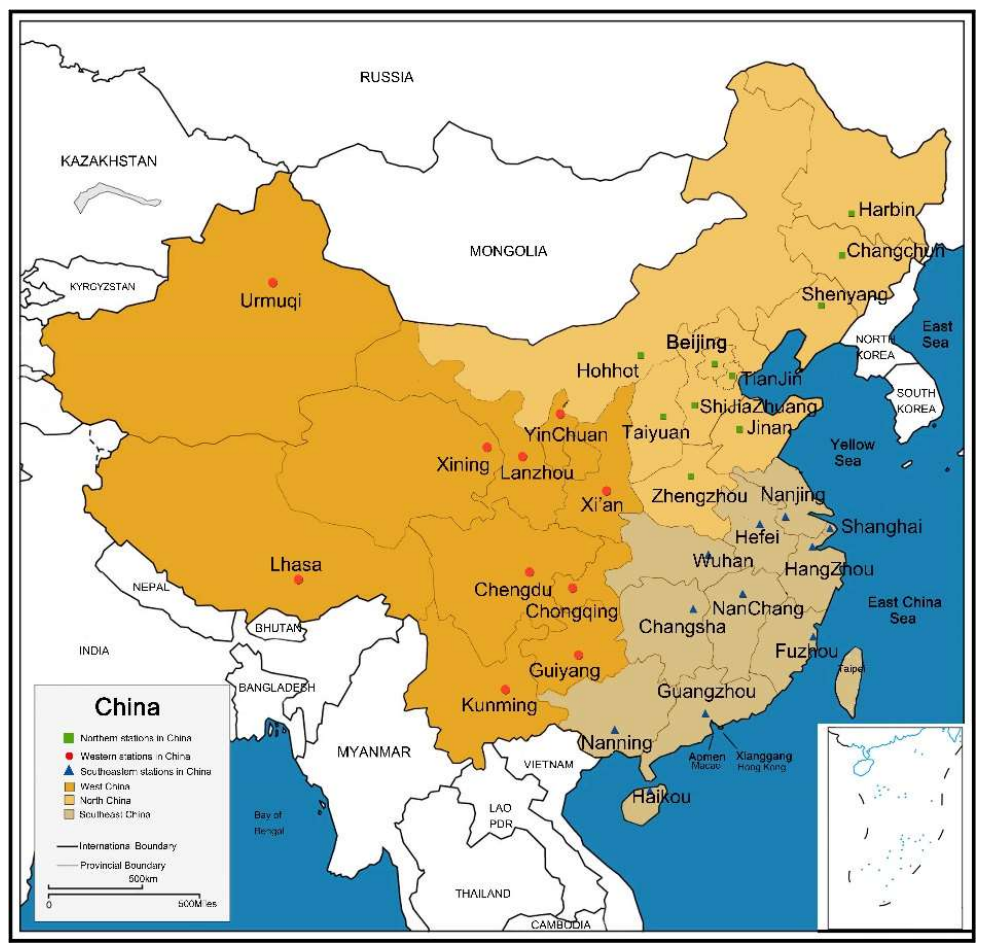

Figure 1. Locations of 31 provincial capital cities in China. 
To the following correct version:

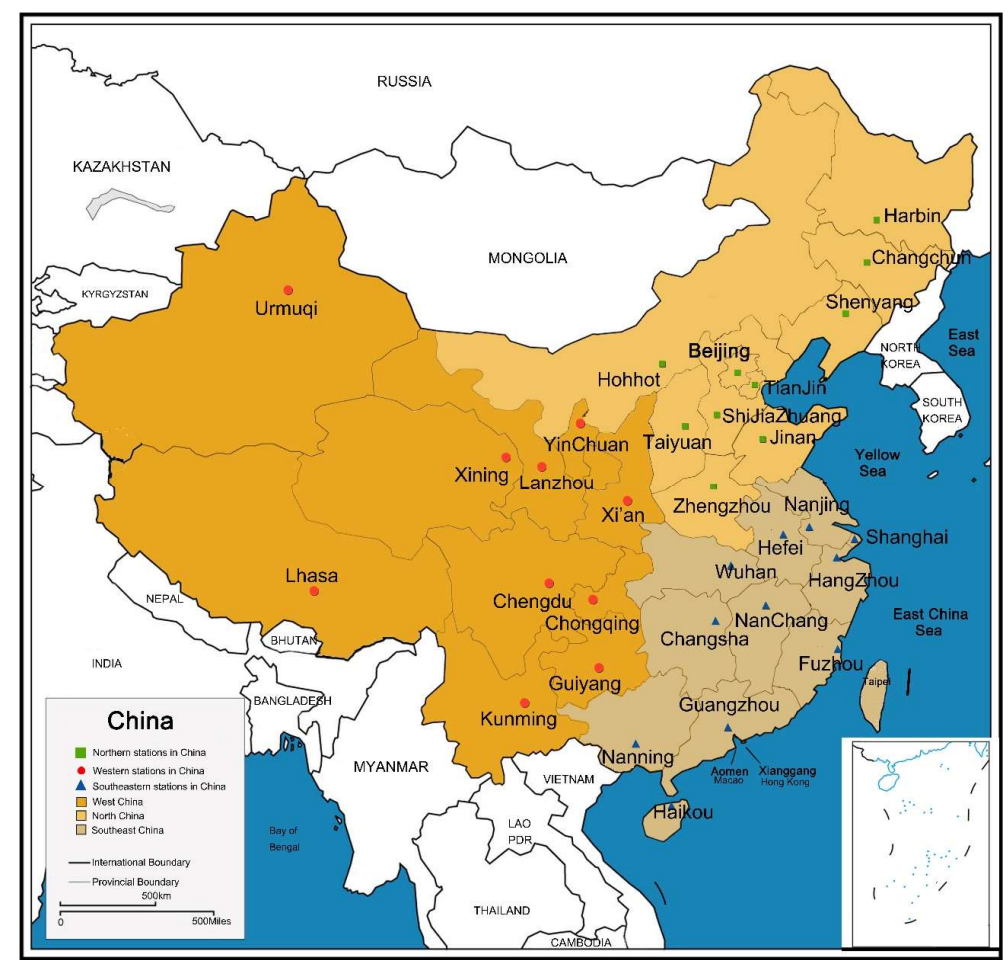

Figure 1. Locations of 31 provincial capital cities in China.

The authors apologize for any inconvenience this has caused to the readers. The changes do not affect the scientific results of this paper. The manuscript will be updated, and the original version will remain online on the article webpage, with a reference to this Correction.

\section{References}

1. Fu, W.; Chen, Z.; Zhu, Z.; Liu, Q.; Qi, J.; Dang, E.; Wang, M.; Dong, J. Long-Term Atmospheric Visibility Trends and Characteristics of 31 Provincial Capital Cities in China during 1957-2016. Atmosphere 2018, 9, 318. [CrossRef]

(C) 2018 by the authors. Licensee MDPI, Basel, Switzerland. This article is an open access article distributed under the terms and conditions of the Creative Commons Attribution (CC BY) license (http:/ / creativecommons.org/licenses/by/4.0/). 